\title{
Is the specialty of general surgery in extinction?
}

\section{La especialidad de cirugía general, ¿una especie en extinción?}

\author{
Erich O.P. Basurto-Kuba* \\ Hospital General de México, Mexico City, Mexico
}

Surgery has accompanied the human being through the course of history, although initially only to solve some pathologies in a bloody manner (wounds, abscesses, fractures, etc.).

The first division in medicine occurs when surgery appears as an independent activity, initially looked down upon, with the so-called barber surgeons, considered unscientific, who were relegated to painful procedures, without anesthesia and with very common development of infections, which is why they had a very bad reputation among the community. However, since the appearance of anesthesia and antisepsis, which were combined by the end of the $19^{\text {th }}$ century and the beginning of the $20^{\text {th }}$, a real specialty began to develop, surgery, which advanced in such a way that it caught up with internal medicine and even surpassed it in terms of projection and prestige. Great surgeons of the likes of Billroth, Kocher, Bassini and Halsted, just to mention a few among many others, emerged in the western world; and in our country, Montes de Oca, Lavista, Urrutia, etc. The advance of surgery was such, that at the beginning of the $20^{\text {th }}$ century, the Nobel Prize was awarded to a surgeon, Dr. Emil Theodor Kocher, for his works on thyroid surgery, where he developed a standardized thyroidectomy technique that significantly reduced surgical morbidity and mortality, as well as for the recognition of the effects on the physiology of patients undergoing thyroidectomy.

These surgeons imposed the rules of patient management and designed and developed surgical techniques, many of which are used to the present day, sometimes only modified by the use of current technology (laparoscopic surgery, staplers, sources of energy, etc.), but that continue maintaining the same principles. Surgeons of those days were general surgeons in the strict sense of the word; they had access to all parts of the human economy that could be surgically approached, although some subdivisions were already starting to appear, out of which the initial ones were obstetrics \& gynecology and orthopedics.

Not only patient care by surgeons was improved or new techniques and instruments were developed, but also, in the field of surgical education, the tutorial way of teaching began to be abandoned and the first surgical schools with a well-established program were opened, with the purpose to produce very well trained general surgeons that could replicate the models of care and teaching in other cities, in a program that was based on trainee surgeons living in the hospital. This is the origin of the concept of general surgery residency, initially promoted in our country in the 1940s at the General Hospital of Mexico by Dr. Aquilino Villanueva. This system was based on pyramidal competition, with the position of head resident being created, which was earned by the most prominent resident doctor. At that time, general surgeons graduated from a formal residence were the most prestigious and respected doctors.

With the explosive evolution of medical knowledge and the rapid development of technology in medicine, it gradually became necessary for surgeons to start

\footnotetext{
Correspondence:

*Erich Otto Paul Basurto-Kuba

Agrarismo, 208-701

Col. Escandon, Del. Miguel Hidalgo

C.P. 11800 , Ciudad de México, México

E-mail: ebasurto_kuba@ hotmail.com
}

Date of reception: 17-05-2018

Date of acceptance: 20-05-2018

DOI: 10.24875/CIRUE.M18000044
Cir Cir. 2018;86:265-267

Contents available at PubMed www.cirugiaycirujanos.com 
devoting themselves more deeply to individually address different parts of the human economy in order to master it. Thus, subspecialties or superspecialties began to appear, with some surgeons completely leaving the rest of the field of general surgery and becoming superspecialists only in one of general surgery disciplines. This is how neurosurgery, surgical oncology, cardiovascular surgery, coloproctology surgery, etc. appeared. Gradually, the general surgeon scope has been pulverized, which went on losing field of action in hospitals where all subspecialties are available, to the point that, in many certified hospitals of national prestige, the resident no longer leaves as a general surgeon, but as a digestive tract surgeon in the best-case scenario.

So much was gradually lost in the field of action that already it is difficult to know what a general surgeon is or what he/she does, both for the medical community itself and much more for society in general, which confuses him/her with a general practitioner and does not identify him/her as a specialist.

The Mexican Association of General Surgery defines a general surgeon as a graduated physician who attends 4 years of general surgery training in a recognized hospital and presents a professional exam at the end of his/her specialty and an exam to obtain certification by the Mexican Council of General Surgery; this way, he/she can practice the specialty by obtaining the General Surgery Specialist Card issued by the General Directorate of Professions of the Ministry of Public Education (SEP - Secretaría de Educación Pública).

Hospitals offer the general surgery specialty to the community of doctors who are aspirants to a residency post and those recognized by the National Autonomous University of Mexico (UNAM - Universidad Nacional Autónoma de México) follow the program known as Single Plan of Medical Specialties (PUEM - Plan Único de Especialidades Médicas) ${ }^{1}$, which, for general surgery, lists a number of areas that should be included in the theoretical and practical teaching of general surgery, such as digestive tract surgery from the esophagus to the anus, the liver and the bile ducts, the pancreas, gynecological pathology and cesarean section, the breast, malignant and benign pathology of all of them, some pathologies of thoracic, vascular and urological surgery, just to name a few. This program is highly ambitious and, unfortunately, very few training hospitals are able to comply with the theoretical part and the much more difficult practical part; therefore, when the residents have to acquire experience on certain pathologies, they must rotate through other training hospitals.

The Mexican Council of General Surgery includes in its certification exam all the subjects contained in the PUEM and, therefore, if a resident wants to obtain the certificate, he/she must be knowledgeable on all of them; it is common to find examinees who confess never having seen some types of surgical pathology they are examined on.

Paradoxically, the above collides with institutional policies at some hospitals where not only the PUEM is not fully complied with, but even hospital authorities forbid that the general surgery department becomes involved in some types of pathology that are supposed to be taught to residents to complete their training, which results in the production of general surgeons with limitations.

Once the resident completes his/her training, he finds $\mathrm{him} /$ herself in two scenarios: working as a general surgeon or continuing his/her training and develop a superspeciality. Given the current conditions in the cities with tertiary care hospitals, where the general surgeon is undervalued and very limited in his/her scope of action, most residents prefer to continue their training, but when the new general surgeons start working in communities lacking tertiary care facilities, they find themselves in the obligation to look after patients with various problems, some of which they did not address during their residency, which may result in unsafe treatments and surgeries.

This is not exclusive to our country, since it is happening all over the world, and it is common to see international forums and publications where the subject of medical teaching and the future of general surgery is addressed. Here, I transcribe some ideas mentioned by Boyarsky et al. ${ }^{2}$ in 1995 in an article published in The American Surgeon with regard to general surgery in the USA: "The future of any medical specialty largely depends on the choice the candidates make; data were obtained from general surgery head residents who graduated in 1990 and their attitudes were compared with those of a similar study conducted in 1985 and the answer was that general surgery residents are increasingly choosing subspecialties, since they do not perceive that being a general surgeon is enough. This has broad implications for the future of general surgery as a specialty that requires significant changes in our residency programs".

We must ask ourselves a series of questions: Should the general surgery specialty continue to be offered in hospitals? Should the general surgery 
PUEM continue to be in force just as it was designed or should it be adapted to the current reality? What kind of general surgery residents do we want to train? What kind of general surgeon does the country need?

I believe that general surgery should not disappear, simply because $80 \%$ of surgical pathologies in the country are resolved by general surgeons and only a small percentage of patients are treated in hospitals that have high specialty clinics. This should make us realize that we must offer more extensive training to our residents.

\section{References}

1. Plan Único de Especializaciones Médicas (PUEM) en Cirugía General. Facultad de Medicina, UNAM, División de estudios de posgrado, Subdivisión de especializaciones médicas, Coordinación de desarrollo curricular. México, D.F. 2009 Plan de estudios aprobado por el Consejo Universitario el 21 de abril de 1994. Coordinación editorial del Dr. Bernardo Pintos Aguilar. Ciudad de México, junio de 2016.

2. Boyarsky AH, Donetz A, Greco RS. The future of general surgery characterized by general surgical chief residents. Am Surg. 1995;61:244-51. 